\title{
Autonomia na formação de professores por meio de gêneros textuais
}

\section{Autonomy in teacher education using a text genre approach}

\author{
Juliana Cristiano Andrade ${ }^{1}$;Vera Lucia Lopes Cristovao²
}

\begin{abstract}
Resumo
Exige-se hoje o desenvolvimento da autonomia dos professores em formação. É por meio da linguagem que o professor reflete acerca de sua prática, pesquisando novas alternativas para a atuação em sala de aula. Por isso, é proposta a abordagem de gêneros (CRISTOVÃO, 2005) para se alcançar esta atividade reflexiva, esta autonomia. Reconhecendo esta possibilidade de se desenvolver a autonomia por meio de uma abordagem de gêneros, este estudo vem discutir, com bases em dados coletados (procedimentos utilizados por professores formadores de diferentes instituições brasileiras) até que ponto a abordagem a partir dos gêneros promove a autonomia dos professores. Também se busca relatar que procedimentos demonstram esse desenvolvimento.
\end{abstract}

Palavras-chave: Formação de professores. Gêneros textuais. Autonomia

\begin{abstract}
Nowadays, it is necessary to develop autonomy awareness in teacher education. It is through language that teachers become able to reflect upon their teaching practice, being able to find new paths for classroom teaching. Due to this situation, it is proposed a text genre approach (CRISTOVÃO,2005) to achieve this reflection, this autonomy. Acknowledging this possibility to develop autonomy through a text genre perspective, this study intends to discuss how autonomy is present in our corpus (procedures used by teacher educators in different Brazilian institutions). And also, we intend to show which procedures convey this development.
\end{abstract}

Keywords: Teaching education. Text genre. Autonomy.

\section{Introdução}

De acordo com pesquisas na área da formação de professores, o professor deveria ser capaz de refletir acerca de seu trabalho. Pelo fato de a sala de aula ser um contexto em que se trabalha com indivíduos de diversos estilos de aprendizagem, o professor deveria estar constantemente refletindo se sua metodologia está coerente com o contexto em que atua. Por isso, faz-se necessário pesquisar as metodologias usadas por professores formadores, para detectar quais destas metodologias melhor desenvolveriam a atividade reflexiva.

Neste estudo, objetiva-se levantar quais são os procedimentos metodológicos de uma abordagem de gêneros que podem ser usados para o desenvolvimento da autonomia de alunos-professores, analisando

1 Bolsista PROIC/UEL no período 2008/2009 e aluna do curso de Letras Estrangeiras Modernas - Inglês da UEL. Email: juliana. cristiano@gmail.com

2 Professora associada do departamento de Letras Estrangeiras Modernas da Universidade Estadual de Londrina. Doutorado e Pós doutorado em Lingüística Aplicada e Estudos da Linguagem pela Pontifícia Universidade Católica de São Paulo.. Email: cristova@uel.br 
questionários à luz da teoria do interacionismo sociodiscursivo e dos conceitos de autonomia.

Primeiramente, discorremos a respeito de conceitos de estudos a formação a respeito da professores (PERRENOUD, 1999; PLACCO, 2006), gêneros textuais à luz do interacionismo sociodiscursivo (ISD) (BRONCKART, 1999, 2003, 2006; CRISTOVÃO, 2005, 2007; CRISTOVÃO; TORRES, 2008), dimensões do trabalho (PLACCO, 2006), e conceitos de autonomia (HOLEC, 1998; HOLEC apud PAIVA, 2006; PAIVA; SENA, 2009; CAMILLERI, 1998). Na sequência, expomos a metodologia utilizada para a análise, apresentamos os resultados e, finalmente, as conclusões.

\section{Formação de Professores e as Dimensões do Trabalho}

De acordo com diversos estudos já publicados acerca da formação de professores de língua inglesa, o professor deveria ter uma formação que priorize a atividade reflexiva. Para Perrenoud, esta atividade reflexiva é exigida porque o professor deveria “construir suas próprias iniciativas" sobre sua prática para poder transformá-la. Por isso, o professor deveria estar em "estado de alerta permanente" (PERRENOUD, 1999, p. 7).

Abordamos neste estudo a questão da necessidade do desenvolvimento da atividade reflexiva na formação de professores, por meio das dimensões de trabalho proposta por Placco (2006, p. 251). A autora propõe que o formador deveria levar em consideração que o aluno-professor necessita de uma formação "articulada", pelo fato de ele ser dotado de "múltiplas dimensões". Essas dimensões são: técnico-científica; formação continuada; trabalho coletivo; dos saberes para ensinar; crítico-reflexiva; avaliativa; ética e política; estética e cultural. As características de cada dimensão são delineadas da seguinte forma:

a) Dimensão técnico-científica: o professor deve ter o conhecimento teórico necessário para atuar no contexto de sala de aula. E, além disso, deve ser capaz de transitar por outros tipos de conhecimento, sendo capaz de articular os mesmos com a teoria para o surgimento de novos conhecimentos. Ex: a disciplina de inglês deveria ser articulada com a geografia, etc.

b) Dimensão da formação continuada: o professor é um profissional que deve estar sempre se atualizando. A autora assinala que esta formação continuada não se refere somente a fazer "cursos e treinamentos", mas sim, a uma "inquietação contínua" na busca de novos conhecimentos.

c) Dimensão do trabalho coletivo: os profissionais da educação, dos quais a autora aponta "professores, dirigentes e outros profissionais da educação", devem reunir-se para fazerem um trabalho transdiciplinar com os professores-aprendizes, trabalhando sua "multiplicidade". Em resumo, a autora afirma que o "trabalho isolado" é ineficaz. Dever-se-ia desenvolver o trabalho cooperativo dos alunos-professores.

d) Dimensão dos saberes para ensinar: o professor deve conhecer seus alunos em sua totalidade (conhecer sua realidade social, emocional, expectativas, conhecimento prévio, experiências vividas, necessidades, etc). Além disso, a autora afirma que o professor não pode acreditar em "certezas acabadas"; ele deveria pensar o processo e o controle da aprendizagem como pertencentes a ambos, aluno e professor. E, por fim, o professor não deveria ver sua formação e sua atuação no mercado de trabalho como processos isolados. Mesmo terminada sua fase de aluno-professor, o professor deveria sempre buscar por novos conhecimentos.

e) Dimensão crítico-reflexiva: o professor deve estar sempre se questionando. Esse questionamento dia respeito não apenas a seu agir em sala de aula, pois cabe-lhe conhecer seu próprio processo de "reflexão meta-cognitiva" para tornar-se um profissional mais crítico. Ou seja, o professor deve conhecer seu próprio processo de aprendizagem para ser capaz de regulá-lo.

f) Dimensão avaliativa: o professor deve desenvolver "habilidades de pesquisa". O professor deve ser capaz de tomar decisões concernentes ao 
que faz em sala de aula e avaliá-las. A autora afirma que o professor deve:

[...] coletar, trabalhar e analisar dados, levantar hipóteses a respeito dos mesmos, propor encaminhamentos, propostas e soluções para as questões encontradas e avaliá-las, a partir de um conjunto de critérios e valores oriundos de suas escolhas e compromissos político-pedagógicos (PLACCO, 2006, p. 259).

g) Dimensões ética e política: o professor deveria ter um entendimento claro dos objetivos do sistema educacional, de seu papel na sociedade de acordo com a política e a ética vigentes. Ao contrário, como afirma a autora, não seria possível "propor e manter projetos políticos pedagógicos consistentes" (PLACCO, 2006, p. 259).

h) Dimensões estética e cultural: o formador deveria proporcionar ao formando um maior conhecimento cultural. De acordo com a autora, é por meio da cultura que se constrói a identidade do professor como profissional e pessoa. Ex. o alunoprofessor deveria ter acesso a uma gama maior de eventos culturais. E não fechar-se somente a comunidade onde vive.

\section{Autonomia e Atividade Reflexiva}

O termo autonomia, de um modo geral, referese à "habilidade de se responsabilizar pela própria aprendizagem" (HOLEC apud PAIVA, 2006, p. 82). Para se alcançar essa responsabilidade proposta por Holec, relacionando ao processo de formação de professores, o aluno-professor deveria ser capaz de tomar suas próprias decisões no que concerne sua aprendizagem, refletir quanto ao seu modo de aprendizagem, sobre o material que utiliza, etc.

Como o autor afirma, a autonomia de um alunoprofessor exigiria:
[...] se responsabilizar por todas as decisões que abarcam todos os aspectos desse aprendizado. Por exemplo:

- determinando os objetivos;

- definindo conteúdos e progressões;

- selecionando métodos e técnicas;

- monitorando o procedimento de aquisição propriamente dita (ritmo, tempo, lugar, etc.);

- avaliando o que tem sido adquirido. (HOLEC apud DOMICIANO; SANTOS, 2003, p. 4, tradução nossa) $)^{3}$.

Portanto, a visão de autonomia proposta por estes teóricos, estaria relacionada com a capacidade de o indivíduo de aprendera aprender, e, consequentemente, no caso dos alunos-professores, de aprender a aprender e a ensinar. De acordo com alguns autores (PAIVA; SENA, 2009; CAMILLERI, 1998), o aprendizado autônomo está relacionado com o ensino de língua para fins significativos e não "[...]apenas exercícios sobre determinados itens gramaticais onde a língua é tratada de forma artificial [...]" (PAIVA; SENA, 2009, p. 33). De acordo com Paiva e Sena (2009, p. 32-33), "A língua deve fazer sentido para o aprendiz em vez de ser apenas um conjunto de estruturas gramaticais.". E para esse efeito, a autora também aponta que, o professor deve partir '[...] da premissa de que a língua deve ser ensinada em toda sua complexidade comunicativa $[\ldots]$ '.

Considerando o ensino por meio de uma visão comunicativa e o ensino da língua de modo a fazer sentido para o aluno, partimos do pressuposto de que esta transformação se daria já no uso de procedimentos metodológicos que priorizam esta abordagem autônoma. Essa transformações envolveriam ações de negociação; de compartilhamento de responsabilidades pela aula entre alunos e professores, transformando os alunos em colaboradores (CAMILLERI, 1998; HOLEC, 1998; PAIVA, 2006; PAIVA; SENA, 2009). Além dessas questões que envolvem a metodologia, seria necessário também um novo papel na atuação de professores.

\footnotetext{
3 " [...] to have, and to hold, the responsibility for all the decisions concerning all aspects of this learning, i.e.:- determining the objectives; - defining the contents and progressions; - selecting methods and techniques to be used;- monitoring the procedure of acquisition properly speaking (rhythm, time, place, etc.); - evaluating what has been acquired."
} 
De acordo com Camilleri (1998), o professor mudaria de papel passando a ser um mediador em sala de aula. Porque, antes de tudo, o próprio professor deveria saber como aprender de forma autônoma. Assim, ele se tornaria responsável, como aponta a autora, por trabalhar em seus alunos aspectos como a autoconfiança, a conscientização de seus processos metacognitivos, entre outros.

Portanto, levando em consideração todos os fatores apontados acima, propomos que uma abordagem de gêneros, de acordo com os pressupostos do ISD, já apresentaria procedimentos que priorizam os conceitos de autonomia apontados, tornando-se uma metodologia interessante para o desenvolvimento da atividade reflexiva.

\section{Gêneros Textuais no Interacionismo Sociodiscursivo (ISD)}

Uma metodologia por meio de gêneros, no ISD, considera que "[...] o desenvolvimento humano se efetiva no agir, o que significa, em primeiro lugar, que todos os conhecimentos construídos são produtos de um agir [...]" (BRONCKART, 2003, p. 51). O agir seria o principal material de trabalho com uma abordagem em gêneros. Este "agir" estaria presente na vida humana nos diversos modos de comunicação, que serão chamados aqui de gêneros (entrevista, conversa, notícia, etc). Estes, conforme Bahktin são "tipos relativamente estáveis de enunciados elaborados por cada esfera social.". No ISD, o estudo deste "agir" humano dar-se-ia por meio do trabalho com gêneros textuais seguindo alguns tipos de análise. De acordo com Cristovão (2005, p. 158):

[...] contexto [...]determina o gênero a ser trabalhado, as capacidades de linguagem que os alunos já dominam e aquelas que precisam ser aprendidas, ao passo que a análise do gênero mostra o funcionamento da linguagem em textos do gênero sendo pesquisado e determina os objetos de ensino a serem evidenciados.
As capacidades mencionadas são as de ação, discursiva e linguístico-discursiva:

1. Capacidades de ação: o indivíduo adapta "sua produção de linguagem ao contexto de produção". Ou seja, o indivíduo deve levar em consideração as características comuns do gênero a ser produzido, representados pelo seu contexto de produção. Como aponta Cristovão (2007, p. 12), "representações do ambiente físico, do estatuto social dos participantes e do lugar social onde se passa a interação." (CRISTÓVÃO, 2007, p. 12)

2. Capacidades discursiva: nesta capacidade o indivíduo faz escolhas quanto a "infraestrutura geral de um texto", trabalhando com, por exemplo, a "escolha dos tipos de discurso e de sequências textuais", ou seja, com o discurso adotado para representar o conteúdo tratado no gênero. Discurso como "processo de verbalização do agir de linguagem” (BRONCKART, 2006, p. 151)

3. Capacidades linguístico-discursiva: nesta capacidade, o indivíduo decide as "operações de textualização" como a "conexão, coesão nominal e verbal", "modalização", "construção de enunciados", etc. Ele trata de questões mais pontuais, questões linguísticas.

Por meio dessas capacidades o formador trabalharia com o reconhecimento do gênero, com a identificação dos discursos recorrentes neste gênero e com os mecanismos linguísticos necessários para a produção do mesmo.

Além desse trabalho com as capacidades de linguagem, o estudo de gêneros utiliza outros procedimentos. Essas capacidades de linguagem que os alunos dominariam ou não, de acordo com Cristovão e Torres (2008, p. 200), poderiam ser identificadas por meio de uma primeira produção do gênero, na qual o aluno-professor ainda não teria acesso a informações sobre este, mas sim, ele partiria de seu conhecimento prévio para a produção do mesmo. Por fim, quando a autora menciona "[...] a análise do gênero mostra o funcionamento da linguagem em textos do gênero 
sendo pesquisado e determina os objetos de ensino a serem evidenciados", este estudo das características recorrentes em determinado gênero a ser trabalhado é que oportunizaria um estudo profundo da linguagem presente no gênero, que permitiria que ele fosse manipulado e produzido de acordo com as necessidades dos alunos-professores.

Consequentemente, os alunos-professores ao desenvolverem essas capacidades, poderiam ser mais críticos com suas produções. Primeiro, pelo fato de uma abordagem de gêneros considerar importante a reescrita de textos quantas vezes quanto necessárias, resultando a cada releitura para a reescrita, uma avaliação do aluno de seu texto junto com os conhecimentos ensinados pelo formador em relação as características recorrentes no gênero. E, segundo, eles moldariam o mesmo de acordo com suas necessidades Desenvolve-se, assim uma autonomia do aluno-professor na manipulação do gênero. Como Bronckart afirma, o "agente" (o professor) desenvolveria:

[...] um duplo processo. De um lado, ele terá que 'escolher' ou adotar o modelo de gênero que lhe parece o mais adaptado ou o mais pertinente em relação às propriedades globais da situação de ação, tal como ele imagina. Por outro lado, ele vai necessariamente adaptar o modelo escolhido, em função das propriedades particulares dessa mesma situação. (BRONCKART, 2003, p. 147).
Ou seja, tudo isso se daria pelo desenvolvimento da atividade reflexiva, no sentido de que a "Reflexão, portanto, envolve perplexidade, dúvida e conflito em situações que demandam participação crítica, análise, tomada de decisão, plano de ação e ações." (CRISTOVÃO, 2005, p. 160). Portanto, o trabalho com gêneros no contexto de formação de professores faria com que eles desenvolvessem sua autonomia. Acreditamos que, a partir do momento que um professor é capaz de avaliar sua própria aprendizagem, este seria capaz de decidir o que é melhor para seus alunos, se há algo para ser mudado em sua prática. Com isso, ele seria capaz de se adaptar a situações diversas do contexto de sala de aula, assim como de sua vida. O trabalho envolve desde o comportamento em sala de aula e fora dela, até o modo como o conteúdo seria trabalhado.

\section{Tipos de discurso}

Um procedimento de análise que utilizamos para este trabalho é a análise dos tipos de discurso. No ISD, estes são apresentados por Bronckart como "[...] segmentos de textos que têm características próprias". Os tipos de discursos são: “o interativo, o teórico, o relato-interativo e a narração" (BRONCKART apud ABREU-TARDELLI, 2006, p. 56).

Bronckart (1999) propõe o seguinte quadro:

Quadro 1 - Tipos de Discurso de acordo com o ISD.

\begin{tabular}{|l|c|c|}
\cline { 2 - 3 } \multicolumn{1}{c|}{} & Mundo da ordem do EXPOR & Mundo da ordem do NARRAR \\
\cline { 2 - 3 } \multicolumn{1}{c|}{} & CONJUNTO & DISJUNTO \\
\hline IMPLICADO & DISCURSO INTERATIVO & RELATO INTERATIVO \\
\hline AUTÔNOMO & DISCURSO TEÓRICO & NARRAÇÃO \\
\hline
\end{tabular}

Fonte: Bronckart (1999)

De acordo com o autor (BRONCKART apud ABREU-TARDELLI, 2006, p. 56-59), cada tipo de discurso tem suas "características e marcas lingüísticas típicas”. Este procedimento de identificação dos tipos de discurso contribui para reconhecer qual o discurso predominante, se os professores se implicam e quais são suas possíveis representações de determinado objeto de estudo, 
neste caso, o uso de procedimentos metodológicos que podem desenvolver a autonomia. Abaixo, aponto as características de cada tipo de discurso:

O discurso implicado e o conjunto podem ser identificados quando o sujeito assume a ação no contexto de produção (o sujeito se implica). Além disso, o discurso é conjunto pelo fato do sujeito verbalizar a ação no momento de produção. Este denominado discurso interativo:

Ex. Converso com meus alunos acerca da possibilidade de alterar o programa da disciplina

Converso: está no presente do indicativo (acontece no momento de produção) e conjugado na primeira pessoa do singular (sujeito assume a ação).

No discurso implicado e disjunto, o sujeito também assume uma posição diante do que enuncia. Porém, este trata de uma situação distante do momento de produção. Denominado discurso relato interativo:

Ex. Conversei com meus alunos sobre a possibilidade de alterar o programa da disciplina.

Conversei: está no pretérito perfeito (distante do momento de produção) e conjugado na primeira pessoa do singular (sujeito assume a ação).

Quando o discurso é autônomo e conjunto, o sujeito verbaliza uma ação da qual ele não assume a autoria. E essa situação é verbalizada no momento de produção. Denominado discurso teórico:

Ex. Conversar com os alunos acerca da possibilidade de alterar o programa da disciplina contribui para uma aprendizagem mais significativa.

Já no discurso autônomo e disjunto, o sujeito também não assume a ação verbalizada. Porém, refere-se a uma ação distante do momento de produção denominado discurso narração:

Ex. Fez-se necessário conversar com os alunos a respeito da possibilidade de alterar o programa da disciplina.
Os tipos de discurso serão utilizados neste estudo para a identificação do discurso predominante, para perceber se os professores se implicam nele e quais são suas possíveis representações sobre procedimentos metodológicos.

\section{Metodologia}

Os dados utilizados foram questionários respondidos por cinco formadores de instituições superiores do Brasil. Três dos questionários são de instituições federais (UFMG, UFU e UFSM) e duas estaduais (UERJ e UEL).

Para a análise das opções metodológicas utilizadas pelos professores formadores, primeiramente foram identificados os procedimentos metodológicos mencionados nas respostas das perguntas 4 e 5 . Além disso, foi feita a análise do tipo de discurso predominante (BRONCKART, 1999, 2003); a análise à luz da teoria das dimensões do trabalho (PLACCO, 2006); E, por fim, efetuou-se a análise à luz dos conceitos de autonomia (HOLEC, 1998; HOLEC apud PAIVA, 2006; PAIVA; SENA, 2009; CAMILLERI, 1998).

\section{Descrição dos Dados: Contexto}

Os participantes do estudo são provenientes de três instituições federais (UFMG, UFU, UFSM) e de duas instituições estaduais (UERJ e UEL). As três federais e uma das estaduais (UERJ) obtiveram o conceito 5 no ENADE.

As informações analisadas foram obtidas de projetos de desenvolvimento institucional (PDIs), projetos políticos pedagógicos institucionais, de um estatuto e, também, de informações retiradas dos sites oficiais. Não conseguimos definir um único documento para a análise de todas as instituições porque nem todas possuíam um documento em comum e, não nos limitamos à análise dos sites porque estes não apresentavam informações suficientes. Ademais, encontramos dificuldades em 
definir os objetivos de cada um desses documentos. Porém, esses têm como objetivo apresentar a organização administrativa e pedagógica das instituições. Por isso, a análise deles diversos documentos se mostrou pertinente. Nosso objetivo com estes era identificar as visões de educação que perpassam estas instituições.

\section{Informações Obtidas}

No PDI da primeira instituição analisada, a Universidade Federal de Minas Gerais (UFMG), afirma-se que ela é comprometida "com o desenvolvimento científico, tecnológico, cultural, econômico e social do Estado, da Região e do País.”. Além disso, consultando outros dados disponíveis no site da instituição, verificamos um dado interessante: a universidade tem 35 cursos de bacharelado; 14 cursos com bacharelado e licenciatura, e somente um curso de licenciatura.

Visualizou-se a maior oferta de cursos com opção de bacharelado, e, também, a preocupação com a formação de profissionais para o desenvolvimento da sociedade (da "região" ao "país"). Concluímos que a instituição parece enfatizar a formação para o mercado de trabalho.

A segunda instituição, a Universidade Federal de Uberlândia (UFU), não disponibiliza muitas informações. O único documento passível de análise foi seu "Estatuto". De acordo com o documento, a instituição parece preocupada com a formação de alunos autônomos, no sentido de formar profissionais que dominem os conteúdos básicos para o exercício de sua profissão e profissionais que saibam lidar com questões da sociedade. Como é afirmado no documento, "I - produzir, sistematizar e transmitir conhecimentos;" e "VII - buscar e estimular a solidariedade na construção de uma sociedade democrática e justa, no mundo da vida e do trabalho;".

A Universidade Federal de Santa Maria (UFSM) afirma ter como missão: "Promover ensino, pesquisa e extensão, formando lideranças capazes de desenvolver a sociedade". Mostra, também, preocupação com a formação humana afirmando compromisso com o "desenvolvimento de capacidades e habilidades capazes de instrumentalizar a participação solidária e coresponsável no contexto social". Além disso, sobre a formação profissional, afirma preocuparse em desenvolver as "capacidades e competências necessárias ao exercício profissional.". Aqui, a autonomia aparece em: "formando lideranças" e "co-responsável".

\section{A Universidade do Estado do Rio de Janeiro} (UERJ), de acordo com seu PPI, afirma ter uma preocupação em formar profissionais com os conhecimentos necessários para o desempenho de sua profissão e, também, conscientes de seu papel na sociedade. Identificamos isto nos termos "profissionais qualificados" (competência técnica), enquanto termos como "compromisso social" e "busca plena da cidadania" se referem a conscientização do profissional de seu papel na sociedade.

A Universidade Estadual de Londrina (UEL) demonstra uma preocupação em ser "disseminadora" de "conhecimento", tendo uma "atuação na geração e na transferência de tecnologia [...] na valorização e na disseminação da produção cultural e científica de Londrina e região." Além disso, de acordo com informações obtidas em seu sítio, é afirmado que a UEL se preocupa em "[...] valorizar o ser humano, a vida, a cultura e o saber; promover o desenvolvimento científico, tecnológico, econômico, social [...]”.

Analisando essas informações, é possível afirmar que esta instituição dá ênfase no objetivo de ser disseminadora de conhecimento. Porém, checando outras informações disponíveis em seu site, identificamos também uma preocupação com a formação de profissionais com competência técnica e consciência crítica.

Como podemos inferir, todas as IES demonstram uma preocupação em desenvolver a autonomia 
de seus alunos, com aparentes variações como no caso da UEL que parece ser uma universidade que dá ênfase à disseminação de conhecimento para o desenvolvimento da sociedade e a UFMG que parece dar ênfase à formação de profissionais habilitados para o mercado de trabalho. Essa observação leva em consideração o contexto da universidade e não dos cursos de letras.

\section{Descrição dos Dados: Participantes}

Três professores formadores das três instituições federais (UFMG, UFU, UFSM) e dois professores das instituições estaduais (UERJ e UEL) Entre eles, quatro formadores da área de língua inglesa e um da área de língua espanhola. Todos possuem formação em Linguística Aplicada, mas cada um trabalha em uma abordagem diferente. $\mathrm{O}$ formador da UFMG trabalha com a aquisição de língua inglesa, pesquisa narrativa, ensino de línguas mediado por computador e gêneros digitais; o formador da UFU com a formação de professores, ensino e aprendizagem de línguas e pesquisa narrativa a respeito de experiências na sala de aula; o formador da UFSM trabalha com pesquisa, multiletramento e práticas discursivas em contextos específicos, teoria e análise crítica de gêneros discursivos, ensino e aprendizagem de línguas (inglês e português), redação, leitura e formação de professores. O formador da UERJ trabalha com a teoria da Análise do Discurso; E, por último, o formador da UEL trabalha com avaliação da aprendizagem de língua estrangeira, teletandem e o ensino de português para estrangeiros. $^{4}$

Quadro 2 - Informações sobre os formadores.

\begin{tabular}{|l|c|c|c|c|}
\hline \multicolumn{5}{|c|}{ Perfil dos Participantes } \\
\hline Sujeitos & Instituição & Formação acadêmica & Tempo na profissão & Tempo na Instituição \\
\hline A1 & UFMG & Doutorado & 38 anos & 24 anos \\
A2 & UFU & Doutorado & 16 anos & 4 anos \\
A3 & UFSM & Pós-doutorado & 26 anos & 25 anos \\
A4 & UERJ & Pós-doutorado & 29 anos & 18 anos \\
A5 & UEL & Doutorado em andamento & & 7 anos \\
\hline
\end{tabular}

Fonte: Autor

Podemos identificar na quadro 2 acima que os formadores selecionados estão nas respectivas IES há algum tempo, supondo-se assim, serem profundos conhecedores de suas práticas.

\section{Procedimento de Coleta de Dados}

Foi enviado por e-mail um questionário para cada professor formador, e ele continha as seguintes perguntas:

\footnotetext{
4 Informações obtidas do currículo Lattes (http://lattes.cnpq.br/) dos respectivos formadores.
} 
Quadro 3 - Perguntas do questionário enviado às formadoras.

01. O que significa para você a relação entre gêneros e formação de professores de língua (estrangeira)?

02. De que modo integra gêneros textuais a suas atividades de formador(a) de professor de língua (estrangeira)?

03. Comente sobre os pontos positivos e negativos que você encontra ao trabalhar com gêneros na formação de professor(es) de língua (estrangeira).

04. Descreva seus procedimentos metodológicos para o trabalho com gêneros textuais e sua relação com os objetivos da disciplina que ministra.

05. Comente sobre alguma(s) atividade(s) que desenvolve com gêneros como formador(a) de professor(es) de língua e a relação com a ementa pela qual é responsável .

06. Que referências elou materiais você usa na realização do trabalho com gêneros?

07. Em relação ao seu desenvolvimento profissional, o trabalho com gêneros na formação lhe acrescenta algo? O quê?

08. Outros comentários.

Como podemos ver, não há uma única pergunta que envolva o conceito de autonomia. Outro ponto, é que os formadores e o pesquisador responsável por estas perguntas se conhecem, então, estes têm consciência do trabalho do pesquisador com o ISD. Assim, podemos supor que os formadores tendem a relacionar suas respostas a estes fatores.

\section{Resultados e Discussão dos Dados}

Procedimentos metodológicos adotados pelos formadores

Os procedimentos metodológicos apontados aqui foram retirados das questões 4 e 5, por serem questões que pedem que o professor mostre explicitamente o que faz em sala de aula.

Quadro 4 - Procedimentos metodológicos mencionados pelos formadores.

\section{Pergunta 04. Descreva seus procedimentos metodológicos para o trabalho com gêneros textuais e sua} relação com os objetivos da disciplina que ministra.

\begin{tabular}{l|l|}
\hline UFMG & Procedimentos mencionados: \\
& - Trabalho com "letramento digital". Professor orienta somente a "parte tecnológica". E, \\
& os alunos "produzem livremente e recebem feedback" dos colegas e do professor. \\
& - No curso "gêneros de eventos acadêmicos", é lida "uma vasta bibliografia sobre os \\
& diversos gêneros".
\end{tabular}


continuação...

apresentação[...]" com a orientação do professor.

- Há, também, o trabalho com o moodle, no qual os alunos podem postar comentários sobre as atividades realizadas em sala de aula.

\section{UFSM Procedimentos mencionados:}

- O professor aponta como critérios para a escolha do que vai ser trabalhado em sala de aula o "que for relevante no momento e geralmente em zigue-zague entre prática e teoria:

- Seminários de leituras para debate teórico

- Seminários de análise grupal, individual ou cruzada de dados nos textos do corpus

- Seminários de debate a respeito de dados para ligar a teoria (conceitos aprendidos) à prática (observação dos textos que circulam na sociedade)

- Elaboração de material didático para transposição didática dos conceitos aprendidos

- Redação de textos teóricos para recontextualizar e rearticular os conceitos aprendidos““

UERJ Procedimentos mencionados:

- Este formador afirma que procura selecionar "materiais diversos" como "textos, impressos, fitas, filmes, etc" e propor "atividades que sempre consideram o trabalho com gêneros e suas formas de textualização. Ele busca relacionar práticas e atividades sociais, a linguagem em uso" seguindo a ementa que propõe o estudo de "elementos sistêmicos" da "narração e sua estrutura"; da "concepção de gênero de discurso: quem enuncia - marcas lingüísticas e de discurso (a pessoa e a designação), do "sujeito que é trazido para compor seu enunciado (discurso relatado)", "o tempo e o espaço (marcas do tempo verbal, lingüística, anáfora); E, por fim, o estudo da "sistematização lingüística: a narração e o uso de pronomes, advérbios e tempos/modos verbais do mundo comentado e do mundo narrado."

\section{UEL Procedimentos mencionados:}

- O professor afirma que sua disciplina não "é de gênero textual propriamente dito".

- Diz que quando trabalhado, o gênero fica "muito mais expositivo, ou seja, com base no meu conhecimento sobre o assunto promovo a discussão e o encaminhamento à medida que julgo necessário."

Também afirma indicar leituras acerca de gêneros textuais para "resolver problemas pontuais oriundos da prática de sala de aula." 
Quadro 5- Procedimentos metodológicos mencionados pelos formadores. Pergunta 05. Comente sobre alguma(s) atividade(s) que desenvolve com gêneros como formador(a)
de professor(es) de língua e a relação com a ementa pela qual é responsável .

\begin{tabular}{|c|c|}
\hline UFMG & $\begin{array}{l}\text { Procedimentos mencionados: } \\
\text { - Trabalha com “narrativas de aprendizagem" relacionada na ementa com os itens: } \\
\text { "aquisição de LE, crenças, estratégias.", que "são usadas para várias atividades de } \\
\text { reflexão sobre processos de aprendizagem ao longo do curso". } \\
\text { - Trabalho com “sign"(cartazes de protesto) onde "os alunos chegam à conclusão que } \\
\text { esse gênero[...] serve para chamar a atenção da imprensa internacional.”. É estudado } \\
\text { neste: "o contexto de uso, forma e conteúdo dos cartazes, incluído temas recorrentes, o } \\
\text { uso do imperativo, os adjetivos recorrentes, e os recursos não verbais (cores, formato de } \\
\text { letras, imagens)." } \\
\text { - Depois, há a produção de "atividades didáticas". }\end{array}$ \\
\hline UFU & $\begin{array}{l}\text { Procedimentos mencionados: } \\
\text { - Trabalho com o gênero painel e abstract. Metodologia: 1. Levantamento de "exemplos } \\
\text { autênticos de painel"; 2. O material é analisado em três partes: O que é, para que serve, } \\
\text { do que trata, sua organização textual e elementos gramaticais. } \\
\text { 3. Alunos produzem primeira versão em inglês E o trabalho envolve a constante "re- } \\
\text { escrita". } \\
\text { - Metodologia dá "margem para discussões sobre perspectivas metodológicas diferentes" } \\
\text { - Os alunos são incentivados a "se inscreverem em eventos locais". O formador afirma } \\
\text { que "é interessante ter os trabalhos dos alunos avaliados pelo comitê organizador do } \\
\text { evento[...]" } \\
\text { - Seu trabalho está relacionado com a ementa porque trabalha com "materiais autênticos } \\
\text { diretamente relacionados com as questões de ensino e aprendizagem de LE" e "o aluno } \\
\text { aprende língua e aprende também as práticas acadêmicas e sociais de sua área de } \\
\text { atuação" e reflete acerca de sua prática. }\end{array}$ \\
\hline UFSM & $\begin{array}{l}\text { Procedimentos mencionados: } \\
\text { - Desenvolve "'Ciclo de redação' que envolve sensibilização, pesquisa etnográfica, } \\
\text { análise, desconstrução e recontextualização de textos acadêmicos, num trabalho de } \\
\text { leitura e redação de gêneros relevantes para que o aluno produza seu texto acadêmico." }\end{array}$ \\
\hline UERJ & $\begin{array}{l}\text { Procedimentos mencionados: } \\
\text { - Exemplo: o trabalho feito com uma letra de música. É pedido que os alunos usem de } \\
\text { outros gêneros para reproduzir o sentido da letra de musica trabalhada. Objetivo: mostrar } \\
\text { aos alunos "possibilidades e impossibilidades do dizer um mesmo fato em variados } \\
\text { gêneros." }\end{array}$ \\
\hline UEL & $\begin{array}{l}\text { Procedimentos mencionados: } \\
\text { - Utiliza como atividade "leituras e (re)conhecimento de importância do trabalho com } \\
\text { gêneros no ensino de LE." }\end{array}$ \\
\hline
\end{tabular}

Fonte: Autor 
Como podemos observar nesses procedimentos selecionados das quadros 4 e 5, eles parecem coerentes com as propostas ensino das respectivas IES, ou seja, há a preocupação em relacionar a teoria com a prática, onde a autonomia dos alunosprofessores parece ser desenvolvida. Somente a última IES, a UEL, não relata qualquer preocupação com este tipo de trabalho. Porém, devemos levar em consideração que as perguntas não pediam em nenhum momento que os professores se posicionassem em relação à questão da autonomia.

Contudo, pudemos notar alguns indícios de autonomia, como será exposto a seguir.

\section{Análise dos Tipos de Discurso Predominantes}

Considerando os tipos de discurso, analisei as perguntas 4 e 5 para verificar qual é o tipo de discurso predominante. Essa análise foi feita diretamente nos questionários.

Quadro 6 - Análise dos tipos de discurso da pergunta 04.

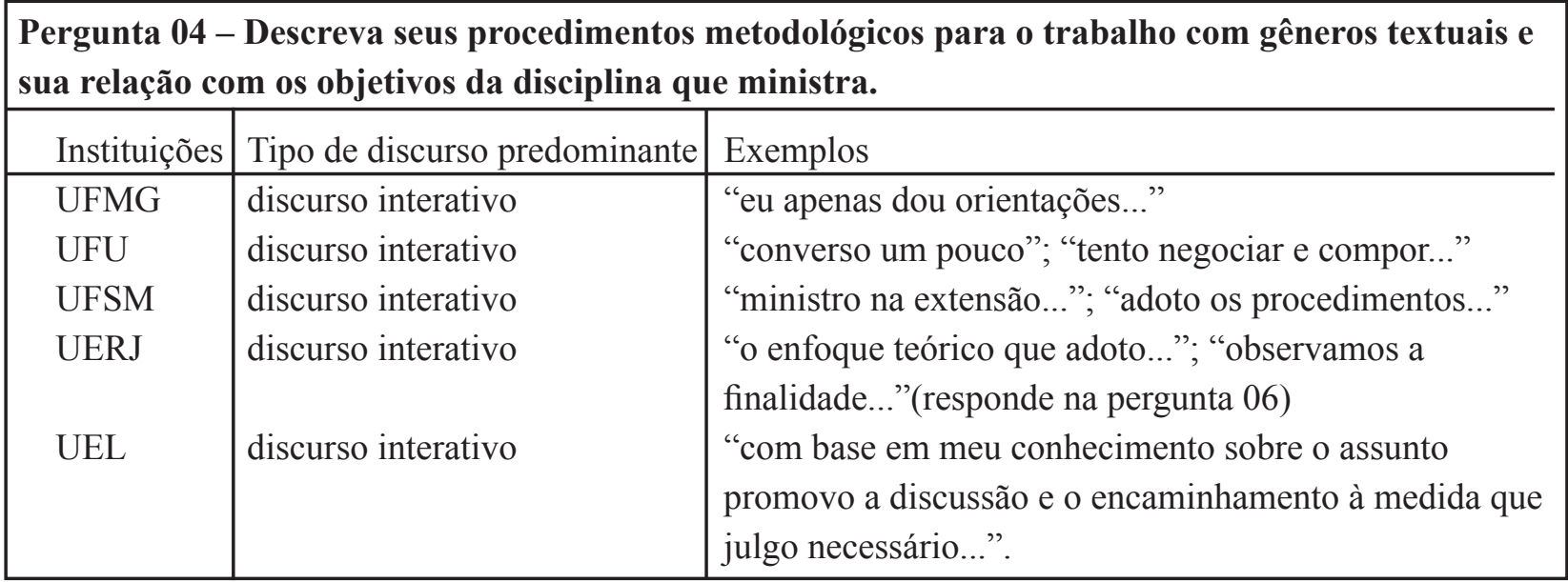

Fonte: Autor

Quadro 7- Análise dos tipos de discurso da pergunta 05.

\begin{tabular}{|c|c|c|}
\hline \multicolumn{3}{|c|}{$\begin{array}{l}\text { Pergunta } 05 \text { - Comente sobre alguma(s) atividade(s) que desenvolve com gêneros como formador(a) } \\
\text { de professor(es) de língua e a relação com a ementa pela qual é responsável. }\end{array}$} \\
\hline \multicolumn{3}{|c|}{\begin{tabular}{|l|l|} 
Tipo de discurso predominante & Exemplos \\
\end{tabular}} \\
\hline UFMG & Discurso teórico & $\begin{array}{l}\text { "Uma atividade é a produção..."; "Eles estudam o } \\
\text { contexto de uso..."; "os alunos chegam à conclusão..." }\end{array}$ \\
\hline UFU & discurso interativo & $\begin{array}{l}\text { "aproveito a oportunidade para trabalharmos...”; } \\
\text { "Fazemos um levantamento...”(fazemos: professor } \\
\text { e alunos) }\end{array}$ \\
\hline UFSM & discurso interativo & "ministro um semestre..."; "Neste curso, desenvolvo..." \\
\hline UERJ & discurso interativo & $\begin{array}{l}\text { "o enfoque teórico que adoto..."; "observamos a } \\
\text { finalidade..."(responde na pergunta 06) }\end{array}$ \\
\hline UEL & discurso teórico & $\begin{array}{l}\text { "Leituras e (re)conhecimento de importância do } \\
\text { trabalho com gêneros no ensino de LE." }\end{array}$ \\
\hline
\end{tabular}

Fonte: Autor 
De acordo com a análise, podemos observar que o discurso predominante em ambas as perguntas é o discurso interativo, e isso demonstra uma possível preocupação por parte dos professores de expor aquilo que eles realmente fazem em sala de aula.

Além disso, vemos aqui um primeiro indício da presençadosconceitos deautonomia:responsabilizarse, tomando suas próprias decisões. Podemos hipotetizar que tendo os formadores uma atitude que incentiva o desenvolvimento da autonomia, consequentemente, os alunos-professores também serão encorajados a desenvolvê-la.

\section{Análise dos Dados à Luz dos Conceitos de Dimensão do Trabalho e de Autonomia}

O critério de análise que utilizamos para fazer a classificação, de acordo com as dimensões do trabalho de Placco, é a comparação e interpretação das ações identificadas(Quadro 1 e 2) com o que é apontado como característica de cada dimensão de trabalho. Unimos as respostas das questões 4 e 5, e fizemos uma análise única de cada instituição:

Quadro 8 - Dimensões de trabalho recorrentes nos dados.

\begin{tabular}{|l|c|c|c|c|c|}
\hline \multicolumn{7}{|c|}{ INSTITUIÇÕES } \\
\hline DIMENSÕES & UFMG & UFU & UFSM & UERJ & UEL \\
\hline Técnico-científica & $\mathrm{X}$ & $\mathrm{X}$ & $\mathrm{X}$ & $\mathrm{X}$ & $\mathrm{X}$ \\
Formação continuada & & & & & \\
Trabalho coletivo & & $\mathrm{X}$ & & $\mathrm{X}$ & \\
Dos saberes para ensinar & $\mathrm{X}$ & $\mathrm{X}$ & $\mathrm{X}$ & $\mathrm{X}$ & \\
Crítico-reflexiva & $\mathrm{X}$ & $\mathrm{X}$ & $\mathrm{X}$ & $\mathrm{X}$ & \\
Avaliativa & $\mathrm{X}$ & $\mathrm{X}$ & $\mathrm{X}$ & $\mathrm{X}$ & \\
Ética e política & & $\mathrm{X}$ & & $\mathrm{X}$ & \\
Estética e cultura & & $\mathrm{X}$ & & $\mathrm{X}$ & \\
\hline
\end{tabular}

Fonte: Autor

De acordo com a tabela, as dimensões presentes em todas as práticas dos formadores são a técnicocientifica, dos saberes para ensinar, crítico-reflexiva e avaliativa. Para alcançar esse resultado, fizemos as seguintes análises:

$\mathrm{Na}$ primeira instituição, a UFMG, percebe-se a presença das dimensões técnico-cientifica, dos saberes para ensinar, crítico-reflexiva e avaliativa. Exemplos:

Dimensão técnico-científica: o formador afirma que é feito a leitura de "uma vasta bibliografia sobre os diversos gêneros"; o formador trabalha com "letramento digital", afirmando que orienta somente a "parte tecnológica".

Dimensões dos saberes para ensinar, críticoreflexiva e avaliativa: os alunos-professores no curso de "letramento digital [...] produzem livremente e recebem feedback" dos colegas e do formador.

Dimensão crítico-reflexiva: formador relata o trabalho com "sign" (cartazes de protesto) nos quais é estudado "o contexto de uso, forma e conteúdo dos cartazes, incluído temas recorrentes, o uso do imperativo, os adjetivos recorrentes, e os recursos não verbais [...]". 
Em relação à segunda instituição, a UFU, foram identificadas as dimensões: técnico-científica, trabalho coletivo, dos saberes para ensinar, críticoreflexiva, avaliativa, ética e politica e estética e cultura ou seja, em quase todas; menos na dimensão da formação continuada. Exemplos:

Dimensão técnico-cientifica: o formador propõe uma metodologia que analisa o gênero em três momentos, como ela propõe: "O que é, para que serve, do que trata, sua organização textual e elementos gramaticais.”.

Dimensão trabalhocoletivo: emum procedimento formador divide "a turma em grupos"; E o trabalho dá "margem para discussões sobre perspectivas metodológicas diferentes".

Dimensão dos saberes para ensinar: "conversar", "negociar" com os alunos.

Dimensão crítico-reflexiva: faz-se o trabalho com moodle, e nele os alunos podem postar comentários sobre as atividades realizadas em sala de aula.

Dimensão avaliativa: os alunos são incentivados a participarem de eventos locais para terem seus abstracts avaliados pelo comitê dos eventos.

Dimensão ética e politica: trabalho com gêneros (painel e abstract) que são utilizados pela esfera acadêmica.

Dimensão estética e cultura: trabalho com gêneros da esfera acadêmica.

$\mathrm{Na}$ terceira instituição, a UFSM, o professor parece trabalhar com as dimensões técnicocientifica, dos saberes para ensinar, critico-reflexiva e avaliativa. Exemplos:

Dimensão técnico-científica: "Seminários de leitura para debate teórico".

Dimensão dos saberes para ensinar, críticoreflexiva e avaliativa: "Ciclo de redação" que envolve "sensibilização, pesquisa etnográfica, análise, desconstrução e recontextualização de textos acadêmicos, num trabalho de leitura e redação de gêneros relevantes para que o aluno produza seu texto acadêmico.".

Em relação à quarta instituição, a UERJ, foram identificadas as dimensões técnico-científica, trabalho coletivo, dos saberes para ensinar, críticoreflexiva, avaliativa, ética e política e estética e cultura, assim como a UFU. Exemplos:

Dimensão técnico-científica: o formador propõe o estudo da estrutura do gênero, marcas que identificam o contexto de produção e as marcas ingüísticas pertencentes ao gênero.

Dimensão do trabalho coletivo, dos saberes para ensinar, critico-reflexiva, avaliativa: o formador aponta a atividade com letra de música, e nessa atividade grupos de alunos tem de reproduzir o sentido da letra de musica trabalhada por meio de outros gêneros.

Dimensão ética e política: o formador se preocupa-se em trabalhar a "linguagem em uso".

Dimensão estética e cultura: o trabalho com a reprodução do mesmo sentido da letra de música para outros gêneros.

Na quinta instituição, a UEL, foi identificada a dimensão técnico-científica. Exemplos:

Dimensão técnico-científica: o professor só menciona "leituras" e aulas "expositivas". Este afirma que isto se dá pelo fato da disciplina não ser de gêneros textuais "propriamente dito". Ademais, afirma que se baseia nas teorias de gêneros para a solução de dúvidas "pontuais", indicando "leituras".

Agora, relacionamos as dimensões do trabalho identificadas nas práticas dos formadores, usando as características de autonomia (HOLEC apud DOMICIANO; SANTOS, 2003, p. 4): 
Quadro 9 - Relação das dimensões identificadas com os conceitos de autonomia.

\begin{tabular}{|c|c|}
\hline Dimensões do trabalho identificadas & \multicolumn{1}{c|}{ Conceitos de Autonomia } \\
\hline Técnico-científica & - selecionando métodos e técnicas. \\
Dos saberes para ensinar & - determinando os objetivos; \\
e & - definindo conteúdos e progressões; \\
Crítico-reflexiva & - monitorando o procedimento de \\
& aquisição (ritmo, tempo, lugar, etc.). \\
& \\
Avaliativa & - monitorando o procedimento de \\
& aquisição (ritmo, tempo, lugar, etc.). \\
& - avaliando o que tem sido adquirido. \\
\hline
\end{tabular}

Fonte: Autor

A dimensão técnico-científica poderia ser relacionada a decisão: "selecionando métodos e técnicas". Pelo fato de esta dimensão focar o conhecimento "sistemático" da língua, mas de modo "significativo" para o professor-aprendiz.

A dimensão dos saberes para ensinar e a dimensão crítico-reflexiva poderiam ser relacionadas com todas as decisões, porque acreditamos que a primeira dimensão é a mais abrangente, tratando da capacidade que todo professor deveria ter: saber ensinar. E, quanto à segunda dimensão, respectivamente, esta é colocada por Placco como responsável pelo "metacognitivo". Ou seja, desde o momento em que são decididos os objetivos até a avaliação deles, o indivíduo deve fazer escolhas.

E, por fim, a dimensão avaliativa poderia ser relacionada com as decisões "monitorando o procedimento de aquisição" e "avaliando o que tem sido adquirido", porque a avaliação envolveria, de acordo com Placco, "analisar" e "levantar hipóteses".

\section{Procedimentos que Incentivam o Desenvolvimento da Autonomia}

Considerando os resultados apresentados, podemos ver que as palavras chaves presentes nas descrições dos procedimentos adotados por estes formadores, relacionados com os conceitos de autonomia seriam: "produzir livremente e receber feedback"; "conversar e negociar com os alunos"; "trabalhar o que for relevante no momento"; "ziguezague entre prática e teoria"; "ligar a teoria (conceitos aprendidos) à prática (observação dos textos que circulam na sociedade)"; "relacionar práticas e atividades sociais, a linguagem em uso"; "atividades de reflexão acerca de processos de aprendizagem"; "a re-escrita"; "trabalho com materiais autênticos"; "aprender as práticas acadêmicas e sociais de sua área de atuação"; “'Ciclo de redação' que envolve sensibilização, pesquisa etnográfica, análise, desconstrução e recontextualização de textos acadêmicos"; "trabalho de leitura e redação de gêneros relevantes para que o aluno produza seu texto acadêmico"; "possibilidades e impossibilidades do dizer um mesmo fato em variados gêneros".

Todas elas parecem estar relacionadas com as características necessárias para a formação de professores e com os conceitos de autonomia. Resumindo, o desenvolvimento dela parece exigir procedimentos que permitam decisões que:

a) sejam negociadas entre alunos e formadores;

b) que se mostrem relevantes para os alunos;

c) que estejam relacionadas à sua área de atuação. 
Dever-se-ia, então, priorizar as atividades nas quais os alunos:

a) poderíam produzir livremente e receber feedback;

b) refletir a respeito do seu processo de aprendizagem, para entender este processo e melhor utilizá-lo;

c) para ser capaz de reproduzir sentido por meio de variados gêneros;

d) Enfim, aprender a lidar com a linguagem em uso.

\section{Conclusão}

Neste estudo, pôde-se perceber que os conceitos de autonomia permeiam todas as dimensões levantadas nos procedimentos metodológicos, baseados em uma abordagem de gêneros textuais, e que os formadores de professores destas instituições parecem preocupados em contribuir com o desenvolvimento da autonomia de seus alunos. Porém, não se pode identificar se estes procedimentos levantados nos questionários realmente deram resultados por não termos informações sobre a evolução dos alunos.

O importante é perceber que, neste recorte analisado, as universidades pesquisadas parecem ter consciência de que o professor de línguas estrangeiras precisa transitar entre o saber aprender e o saber ensinar. E isso é percebido desde o momento em que são descritos os objetivos de cada universidade, até o momento em que são feitas as análises. Enfim, é perceptível a contribuição dos procedimentos para a formação de professores capazes de tomar suas próprias decisões de professores cidadãos, capazes de transformar seus alunos, assim como eles, em cidadãos críticos-reflexivos.

\section{Referências}

A B R E U-TARDEL LI, Líli a S a n tos. Trabalhodoprofessor@chateducacional.com.br: aportes para compreender o trabalho do professor iniciante em EAD. 2006. Tese (Doutorado em Linguística Aplicada e Estudos da Linguagem) Pontifícia Universidade Católica de São Paulo, São Paulo.

BRONCKART, Jean-Paul. Atividade de linguagem, discurso e desenvolvimento humano. Campinas: Mercado das Letras, 2006.

Atividade de linguagem, textos e discursos: por um interacionismo sócio-discursivo. São Paulo: EDUC, 1999.

- Gêneros textuais, tipos de discursos e operações psicolingüísticas. Revista de Estudos da Linguagem, Belo Horizonte, v. 11, n. 1, p. 49-69, jan./jun. 2003.

CAMILLERI, Antoinette. Introducing learner autonomy in initial teacher training. In: HOLEC, Henry; HUTTUNEN, Irma. Learner autonomy in modern languages. Strasbourg: Council of Europe: Langues Vivantes, 1998. p. 87-101.

CRISTOVÃO, Vera L. L. Aprendendo a planificar o próprio trabalho: gêneros textuais na formação de professores de língua estrangeira. In:

Gêneros textuais: teoria e prática II. Palmas: Kaygangue, 2005. p. 153-162.

CRISTOVÃO, Vera L. L. Modelos didáticos de gênero: uma abordagem para o ensino de língua estrangeira. Londrina: EDUEL, 2007.

CRISTOVÃO, Vera L. L.; TORRES, Ana Cecília da G. Gênero textual como instrumento para o engajamento do aprendiz no processo de avaliação da produção escrita. In: ORTENZI, Denise I. B. G.; GIMENEZ, Kilda M. P.; GIMENEZ, Telma N.; CRISTOVÃO, Vera L. L.; FURTOSO, Viviane, B. Roteiros pedagógicos para a prática de ensino de Inglês. Londrina: EDUEL, 2008. p. 37-57

DOMICIANO, Regina M. G.; SANTOS, Claudia Broietti. Autonomia em aprendizagem em Línguas Estrangeiras (Inglês): uma análise dos deslocamentos do conceito e das práticas 
pedagógicas. In: NICOLAIDES, C. et al. (Org.). $O$ desenvolvimento da autonomia no ambiente de aprendizagem de línguas estrangeiras.Pelotas: UFPEL, 2003. p. 50-69.

HOLEC, Henry. Main features of the educational approach adopted. In: HOLEC, Henry; HUTTUNEN, Irma. Learner autonomy in modern languages. trasbourg: Council of Europe: Langues Vivantes, 1998. p. 23-32.

PAIVA, Vera L. M. O.; SENA, Antonio E. L. L. $\mathrm{O}$ ensino de língua estrangeira e a questão da autonomia. In: CÂNDIDO, Diógenes L. (Org.). Ensino e aprendizagem de língua inglesa: conversas com especialistas. São Paulo: Parábola Editorial, 2009. p. 31- 46.

PAIVA, Vera. L. M. O. Autonomia e complexidade. Linguagem \& Ensino, v. 9, n. 1, p. 77-127, 2006.

PERRENOUD, Philippe. Formar professores em contextos sociais em mudança: prática reflexiva e participação crítica. Revista Brasileira de Educação, Belo Horizonte, n. 12, set./out./nov./dez. 1999. Disponível em: <http://www.anped.org.br/rbe/rbe/ rbe.htm>. Acesso em: 2 mar. 2009.

PLACCO, Vera Maria Nigro de Souza. Perspectivas e dimensões da formação e do trabalho do professor. In: SILVA, Aida Maria Monteiro; MACHADO, Laêda Bezerra; MELO, Márcia Maria de Oliveira; AGUIAR, Maria da Conceição Carrilho de. (Org.) Educação formal e não-formal, processos formativos, saberes pedagógicos: desafios para a inclusão social. Recife: ENDIPE, 2006. p. 251-261. 
Andrade, J. C.; Cristovao, V. L. L. 